\title{
A simplified electrical model of small PEM fuel cell
}

\author{
Andrea, E.; Mañana, M.; Ortiz, A.; Renedo, C.; Eguíluz, L.I.; Pérez, S.; Delgado, F. \\ Department of Electrical Engineering \\ E.T.S.I.I.T. University of Cantabria \\ Avda. Los Castros s/n \\ 39005 Santander, Cantabria \\ Spain \\ Phone: +34942201378 Fax: +34942201385 Email: mananam@unican.es
}

\begin{abstract}
This research work is devoted to the development of an electrical and mathematical model able to simulate the static and transient phenomena in a small power polymer electrolyte membrane fuel cell (PEM) system. At present, there are different electrochemical models available to capture the steady state behavior by estimating the equilibrium voltage for a particular set of operating conditions. However, it is difficult to find models capable of describing transient phenomena. Dynamic models are very interesting from a practical point of view when the loads exhibit large variations. Some examples are powertrains of land-based vehicles or submarines. In that cases, the output power from the fuel cell shows large variations during acceleration and deceleration.
\end{abstract}

Keywords. fuel cell, PEM fuel cell, distributed generation, dynamic model

\section{Introduction}

The fuel cell is one of the most promising sources of renewable energy. They can be considered as green power because they are environmentally clean, have low emission of oxides of nitrogen and sulfur and at the same time, they can operate with a very low level of noise. In addition, they can provide energy in a controlled way with higher efficiency than conventional power plants.

The fuel cell transforms hydrogen into dc power. There are different technologies of fuel cell. They are commonly classified according to temperature and/or the type of electrolyte. Among others, low-temperature fuel cell includes proton exchange membrane (PEM). The estructure of a PEM fuel cell is shown in fig. 1.

From the point of the electrochemical model of PEM fuel cell, there are different approaches that can be followed [1-6].

\section{Proton exchange membrane (PEM) fuel cell}

There are different fuel cell technologies that have been successfully used. Among others, the polymer electrolyte (PE) fuel cell, also named proton exchange membrane (PEM) fuel cell, can be considered a good alternative for the use aboard of electric vehicles in

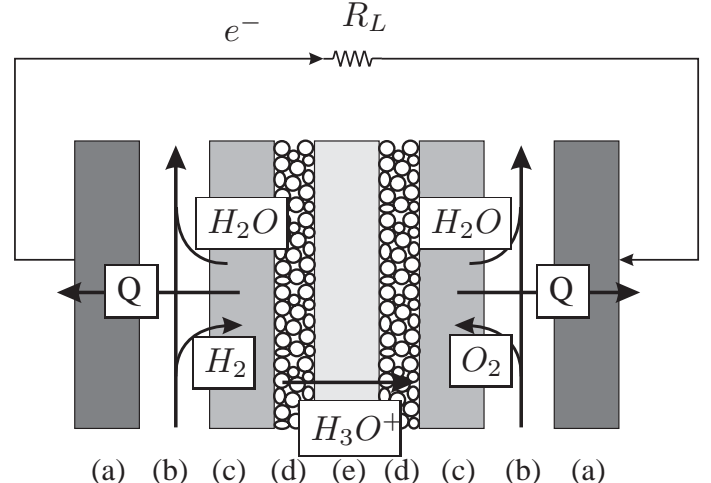

Figure 1. Estructure of a PEM fuel cell. (a) Bipolar plate; (b) Gas flow channel; (c) Electrode layer; (d) Catalyst layer and (e) polymer layer.

which simplicity, high specific power and rapid start-up at different temperatures have a significative importance [7].

A PEM fuel cell is constituted by a stack with a central membrane able to conduct protons. The external layers work as two electrodes. The set of layers is pressed by two conductive plates containing some channels in which the reactants flow.

A basic diagram showing the estructure of the cell is shown in Fig. 1. The main elements inside the cell are: conductor plates, electrodes and membrane. The electrodes are composed by a gas diffusion layer and a catalyst layer. Both layers have a porous, partially hydrophobic, structure.

Air is fed to the cathodic layer, and hydrogen is fed to the anodic one. The central membrane works as a electrolyte that performs both the functions of transferring $\mathbf{H}^{+}$from the anode to the cathode and reactant separation. The electrochemical reactions involved are summarized below, 


$$
\begin{gathered}
2 \mathrm{H}^{+}+\frac{1}{2} \mathrm{O}_{2}+2 e^{-} \rightarrow \mathrm{H}_{2} \mathrm{O} \\
\mathrm{H}_{2}+\frac{1}{2} \mathrm{O}_{2} \rightarrow \mathrm{H}_{2} \mathrm{O}
\end{gathered}
$$

Ec. (1) describes the chemical reaction at the anode. The electrons are transferred to the platinum layer and protons to the central membrane. Ec. (2) shows what happens at the cathode. The oxygen reacts with the protons coming from the membrane and with the electrons fed by the catalyst. The result is water. Finally, ec. (3) shows the overall reaction.

\section{Circuit model of PEM fuel cell}

A typical PEM fuel cell has a V-I characteristic at room temperature and normal air pressure like the characteristic shown in Fig. 2. There are some factors that produces losses (voltage drop) in a fuel cell. Such losses will cause the cell voltage to be less than its ideal potencial. There are three main sources of losses:

1) Activation polarization.

2) Ohmic polarization.

3) Concentration polarization.

The output voltage of the PEM fuel cell is defined by the following equation [4], [8],

$$
E=N\left(E_{0}+\frac{R T}{n F} \ln \left\{\frac{P_{H_{2}}\left(\frac{P_{O_{2}}}{P_{s t d}}\right)^{1 / 2}}{P_{H_{2} O_{c}}}\right\}-L\right)
$$

where

E Stack output voltage.

$\mathrm{N} \quad$ Number of cells in stack.

$E_{0} \quad$ Cell open circuit voltage at standard pressure.

$\frac{R T}{n F} \quad$ The Tafel slope [8], usually in the range from 0.03 to $0.12 \mathrm{~V}$ for $24{ }^{\circ} \mathrm{C}$. $\mathrm{R}$ is the universal gas constant, $\mathrm{F}$ is Faraday's constant, $\mathrm{T}$ is the operating temperature and $n=2$ is the number of transferred electrons in the electrochemical reaction defined by ec. 1 .

$P_{H_{2}} \quad$ Partial pressure of hydrogen inside the cell.

$P_{\mathrm{O}_{2}} \quad$ Partial pressure of oxygen inside the cell.

$P_{\mathrm{H}_{2} \mathrm{O}_{c}}$ Partial pressure of gas water.

$P_{\text {std }} \quad$ Standard pressure.

L Voltage losses.

The PEM fuel cell 's voltage losses L have the following contributions:

- Activation losses. Due to the slowness of the reactions taking place inside the cell. This term can be reduced by maximizing the catalyst contact area for reactions.

- Internal current losses. Due to the leakage of electrons that pass through the membrane to the cathode side instead of flowing through the electric load.

- Resistive losses. Due to the current flow through the resistance of the whole electrical circuit including the membrane and the interconnections. This term can be reduced if the membrane is well hydrated.

- Mass transport or concentration losses. Due to gas concentration changes at the surface of the electrodes.

Hence, the term including voltage losses $(L)$ can be expressed as,

$$
\begin{aligned}
L= & \frac{R T}{\alpha n F} \ln \left(\frac{i+i_{n}}{i_{0}}\right) \\
& +r\left(i+i_{n}\right)-\frac{R T}{n F} \ln \left(1-\frac{i+i_{n}}{i_{L}}\right)
\end{aligned}
$$

where

$i \quad$ Output current density.

$i_{n} \quad$ Internal current density related to internal current losses.

$i_{0} \quad$ Exchange current density related to activation losses.

$i_{l} \quad$ Limiting current density related to concentration losses.

$r \quad$ Area specific resistance related to resistive losses.

Fig. 2 also shows the regions and the qualitative result of each one of the causes of losses.

Cell voltage (V)

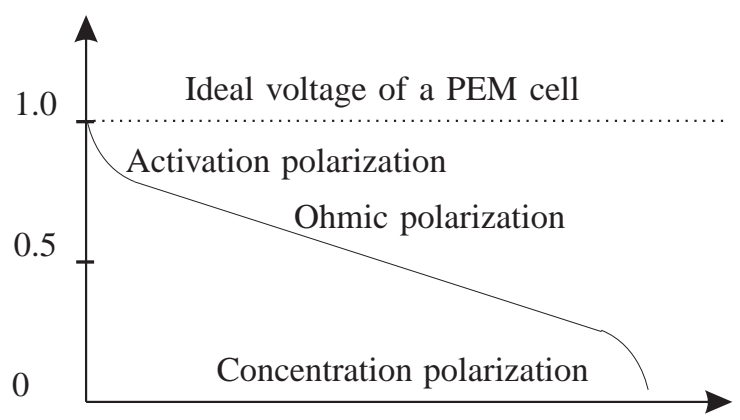

Current density

Figure 2. V-I characteristic of a single PEM fuel cell.

The V-I characteristic shown in fig. 2 can be modeled using the equivalent circuit [6] shown in fig. 3 .

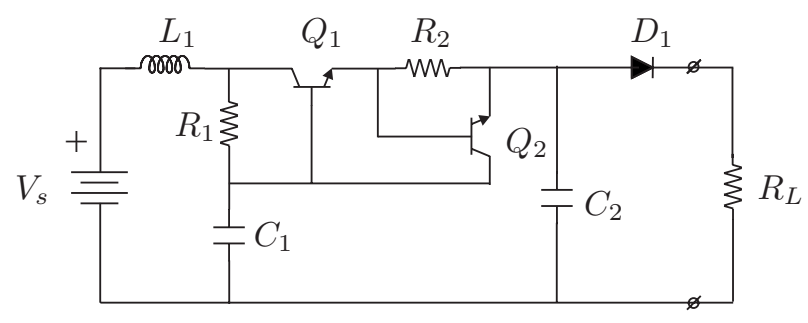

Figure 3. Equivalent circuit of the PEM fuel cell [6]. 


\section{Experimental test facility and results}

The fuel cell is a preassembled StaXX2 model from h-tec [9]. The basic parameters of the fuel cell are summarized in table I.

TABLE I

TECHNICAL DATA OF FUEL CELL STAXX2.

\begin{tabular}{|l|l|}
\hline Parameter & value \\
\hline $\mathrm{HxWxD}(\mathrm{mm})$ & $100 \times 200 \times 250$ \\
\hline Weight & $1.110 \mathrm{~g}$ \\
\hline Electrode area & $4 \times 16 \mathrm{~cm}^{2}$ \\
\hline Power & $2 \mathrm{~W}$ at $2.0 \mathrm{~V}$ \\
\hline Generated voltage & $1.6-3.84 \mathrm{~V}$ \\
\hline Short-circuit proof & yes \\
\hline
\end{tabular}

The fuel cell has been put to the test using a test system facility composed by the fuell cell, a controlled load and a measurement and control unit. The test system facility has a block diagram that is shown in fig. 4. The basic idea can be summarized as follows: the variable load $R_{L}$ can be adjusted in order to compute the v-i characteristic.

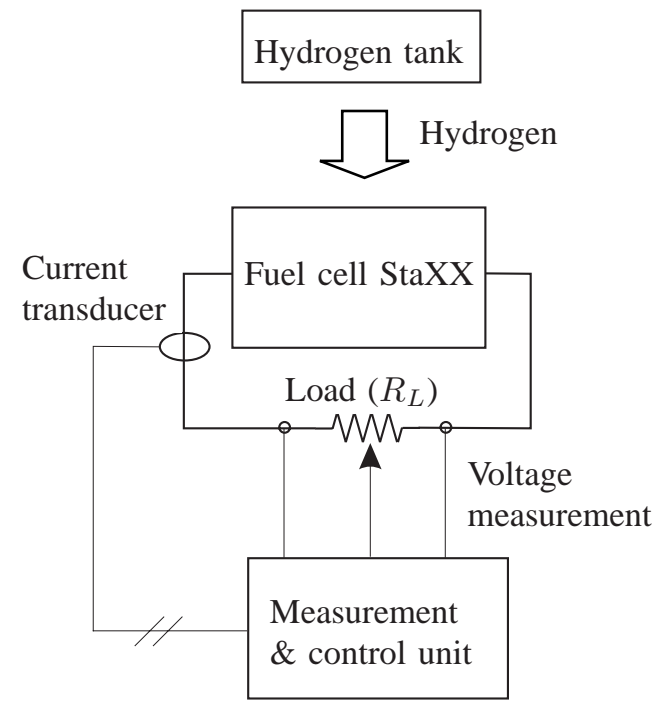

Figure 4. Laboratory test facility.

Fig. 5 shows the laboratory test facility with the hydrolyzer, the fuel cell and the measurement and control units.

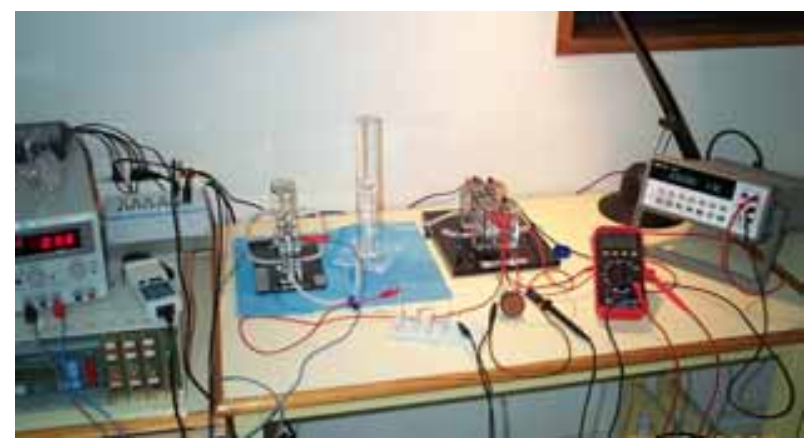

Figure 5. Laboratory test facility.
Fig. 6 shows the measured V-I characteristic of the fuel cell at $25{ }^{\circ} \mathrm{C}$.

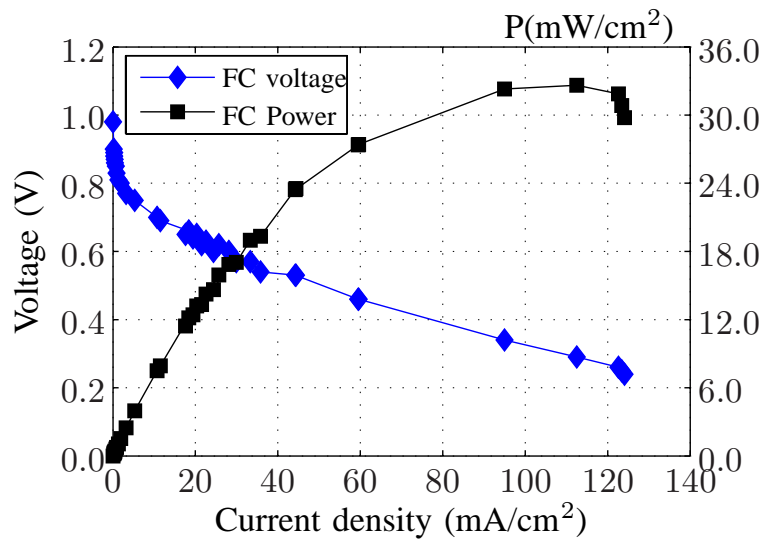

Figure 6. V-I characteristic of a single PEM fuel cell.

Fig. 7 shows the voltage at each cell of the stack with different load conditions. This test highlights the necessity of controlling all the cells inside the stack because the individual behavior is a function of the current density. The relative deviation of each voltage with the mean value can reach values up to $7 \%$ when the current density is over $60 \mathrm{~mA} / \mathrm{cm}^{2}$.

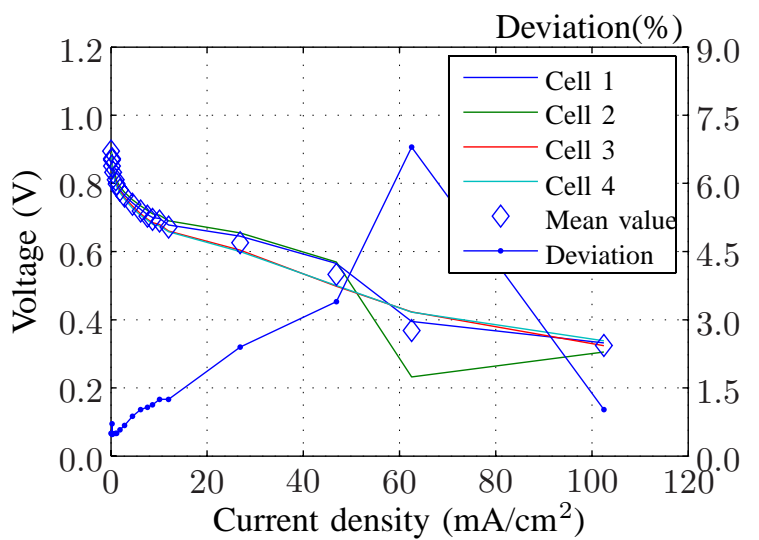

Figure 7. Voltage in each cell of the stack.

Fig. 8 shows the V-I characteristic of both simulated [10] and measured fuel cell. The irregularities of the measured voltage between 20 and $40 \mathrm{~mA} / \mathrm{cm}^{2}$ has been estimated that are produced because the utilization of different test systems.

The theoretical approach has been obtained estimating the coefficients in ec. 4 and 5,

$$
\begin{aligned}
E= & 1.219-0.40-0.025679 \ln (i+0.001751) \\
& -0.0037 i+0.0128395 \ln \left(1-\frac{i}{i_{l}}\right)
\end{aligned}
$$

The V-I characteristic of the theoretical approach obtained with ec. 6 is included in Fig. 8. This figure shows that both the electrical circuit and the theoretical model have a good response in static conditions. From 


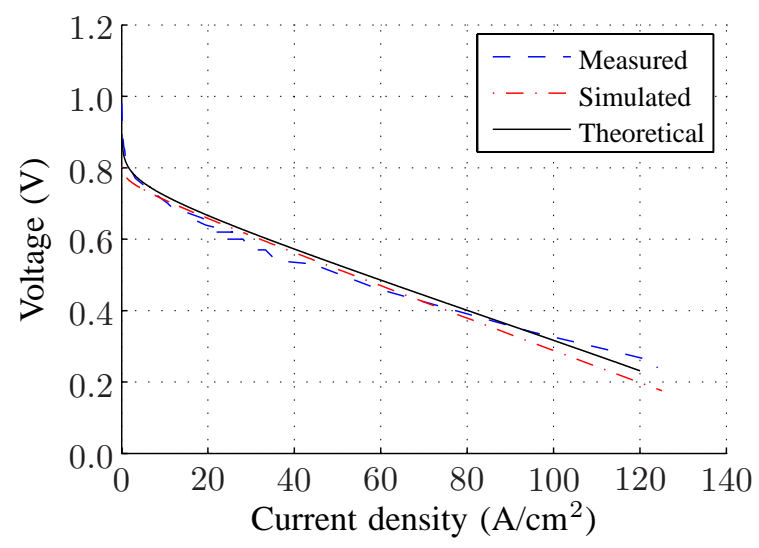

Figure 8. V-I characteristic of measured vs simulated fuel cell.

the point of view of the dynamic conditions, Fig. 9 shows the dynamic behavior of the model during a instantaneous variation of the load from open circuit to $3 \Omega$. In addition, Fig. 10 shows the real behavior of the fuel cell in the same operating conditions.

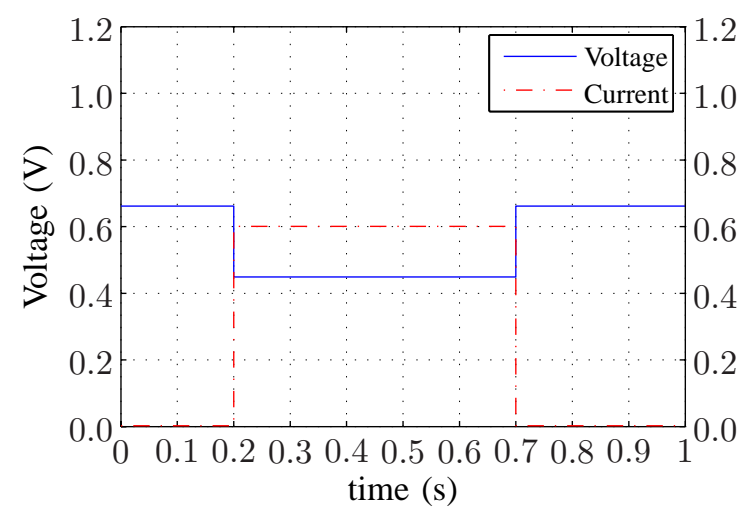

Figure 9. Voltage and current snapshot during a transient from infinite to $3 \Omega$ (simulated).

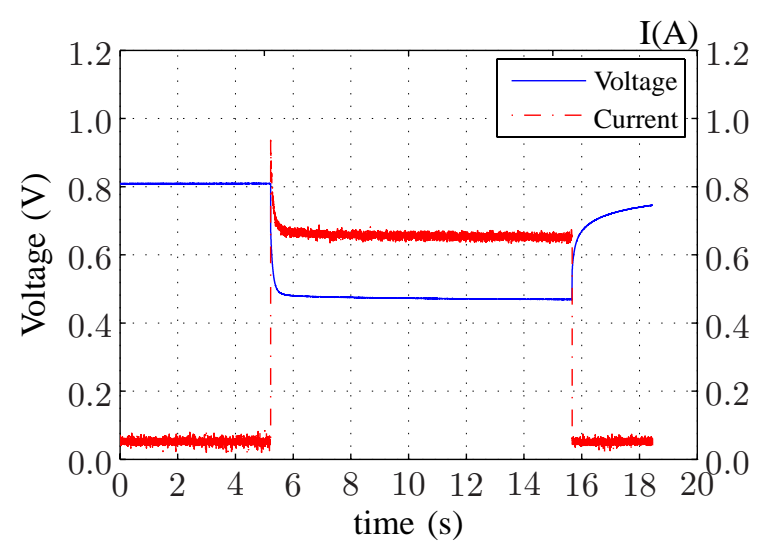

Figure 10. Voltage and current snapshot during a transient from infinite to $3 \Omega$ (measured).

\section{Conclusions}

A basic model for a small power PEM fuel cell has been analyzed. The model is based on pasive elements and a diode and a pair of BJTs for modeling the non-linear part of the V-I characteristic. The model has been validated by comparing the simulation and the measurements obtained from a small power fuel cell by a test system facility. It has been shown that the behavior of the static model is quite accurate. However, the model should be improved in order to have a good dynamic response.

\section{Acknowledgment}

The authors would like to thank the support of the Spanish Government under the PROFIT research project CIT-120000-2005-19.

\section{References}

[1] J. Baschuk and X. Li, "A general formulation for a mathematical pem fuel cell model," Journal of Power Sources, vol. 142, no. 1-2, pp. $134-153,2005$.

[2] P. Pathapati, X. Xue, and J. Tang, "A new dynamic model for predicting transient phenomena in a pem fuel cell system," Renewable Energy, vol. 30, no. 1, pp. 1 - 22, 2005.

[3] J. Golbert and D. R. Lewin, "Model-based control of fuel cells: (1) regulatory control," Journal of Power Sources, vol. 135, no. 1-2, pp. 135 - 151, 2004.

[4] L.-Y. Chiu, B. Diong, and R. S. Gemmen, "An improved small-signal model of the dynamic behavior of pem fuel cells," IEEE Transactions on Industry Applications, vol. 40, no. 4, pp. $970-977,2004$.

[5] D. Yu and S. Yuvarajan, "A novel circuit model for pem fuel cells," Conference Proceedings - IEEE Applied Power Electronics Conference and Exposition - APEC, vol. 1, pp. 362 - 366, 2004.

[6] S. Yuvarajan and D. Yu, "Characteristics and modeling of pem fuel cells," Proceedings - IEEE International Symposium on Circuits and Systems, vol. 5, pp. -880-883 -, 2004.

[7] M. Ceraolo, C. Miulli, and A. Pozio, "Modelling static and dynamic behaviour of proton exchange membrane fuel cells on the basis of electro-chemical description," Journal of Power Sources, vol. 113, no. 1, pp. 131 - 144, 2003.

[8] H. Liebhafsky and E. Cairns, Fuel cells and fuel batteries, J. W. . Sons, Ed., 1968, vol. 1.

[9] Fuel cell StaXX. Operating instructions.

[10] M. Engelhardt, SwitcherCAD III. User's Manual. 